\title{
KREATIVITAS, INOVASI, DAN PRODUKTIVITAS DI ERA MERDEKA BELAJAR MELALUI TRANSPFORMASI E-LEARNING
}

\author{
Ike Dian Puspita Sari ${ }^{1)}$, Indrawati Pusparini ${ }^{2)}$, Adi ${ }^{3)}$ \\ IKIP Budi Utomo \\ 1)ikedianpuspitasari@budiutomomalang.ac.id ${ }^{2)}$ Indrawatipusparini@budiutomomalang.ac.id \\ 3)adi@budiutomomalang.ac.id
}

\begin{abstract}
The development of science and technology increasingly encourages renewal efforts in the use of technological results in the learning process. Media that can support learning include computer media. In the era of pandemic, distance learning is very much needed and recommended to suppress the spread of COVID 19. There are many learning media platforms that can be used during distance learning today. Teachers are required to develop skills in making media or developing learning media because the methods and learning media used by teachers greatly affect the results of the teaching and learning process. Thus, there is a need for training in making online-based learning media that will be used during a pandemic and distance learning.
\end{abstract}

Keywords: Creativity, innovation, productivity, e-learning transformation

\section{ANALISIS SITUASI}

Munculnya era industri 4.0 telah mengubah paradigma dalam berbagai bidang termasuk dunia pendidikan secara signifikan. Dimana pada masa sebelumnya yang jika pendidikan dilaksanakan secara klasik hanya dilakukan di ruang kelas maka di era industri 4.0 ini mengartikan pendidikan tidak lagi hanya berkutat pada kegiatan belajar di kelas saja namun belajar tanpa batas waktu dan tempat. Era industri 4.0 memunculkan kondisi artificial intelligence, dengan kondisi tersebut mempengaruhi berbagai aktifitas manusia saat ini. Kondisi tersebut ditambah dengan seiringnya kemajuan dalam bidang science dan teknologi menambah revolusi dalam aktifitas kita saat ini.

Salah satu dampak dari perubahan tersebut adalah dalam bidang pendidikan untuk era industri 4.0 dimana nilai tidak lagi menjadi konsen utamanya namun skill, Kompetensi, karakkter dan kepribadian menjadi fokus utama pendidikan di era ini. Tuntutan pendidikan di abad 21 ini menuntut adanya kompetensi dan skill peserta didik setidaknya memiliki keterampilan berkolaborasi, berfikir kritis dan memiliki kreatifitas dan inovasi. Menteri pendidikan Nadiem Makariem dalam pidatonya beberapa waktu yang lalu menjelaskan terkait kebutuhan bidang keilmuan untuk masa depan yang meliputi antara lain Bahasa Intenasional, Statistik dan psikologi.

Secara sederhana dapat diartikan bahwa bahasa internasional dibutuhkan dalam membangun komunikasi dan kolaborasi dalam konteks global, kemudian statistik diganakan sebagai dasar berfikir dengan berbasis pada kebenaran data dan psikologi adalah terkait dengan bagaimana membangun sikap dan karakter. Pada akhirnya pendidikan di era dunia industri 4.0 tidak hanya lagi berfokus pada nilai hasil belajar semata namun menuntut adanya skill, kompetensi dan karakter dari peserta didik itu sendiri karena perkembangan dunia yang begitu cepat dengan berbagai macam perubahannya.

Tantangan bagi kita semua tentunya untuk menghadapi adanya perubhana-perubahan yang terjadi khususnya dalam dunia pendidikan bagaimana membangun kualitas pendidikan di masa sekarang dan yang akan 
datang menjadi lebih baik dan berkualitas. Mengutip kalimat Richard W. Riley (U. S. Secretary Of Education) terkait dengan trnasformasi paradigma pendidikan saat ini dan akan datang menjelaskan bahwa "Hari ini kita menyiapkan para siswa untuk memasuki dunia kerja yang belum tercipta, dengan menggunakan teknologi yang belum ditemukan, untuk menyelesaikan permasalahan yang juga belum diketahui".

Merdeka belajar dapat diwujudkan dengan menggali potensi para pendidik dan peserta didik untuk berinovasi dan meningkatkan kualitas pembelajaran secara mandiri. Apa artinya? Disinilah kualitas guru menjadi kunci utama. Guru yang berkualitas dan berkompeten dapat mendorong kesuksesan belajar siswa. Guru tidak akan bisa digantikan oleh teknologi. Teknologi hanyalah alat bantu guru dalam meningkatkan potensi mereka dan menjadi penggerak terbaik untuk mereka dapat memimpin pendidikan di sekolah. Oleh karena itu, konsep pelatihan guru perlu disesuaikan dengan kurikulum yang lebih fleksibel. Kurikulum yang dapat mendorong para guru agar dapat memilih materi atau metode pembelajaran dengan kualitas tinggi, tetapi sesuai tingkat kompetensi, minat, dan bakat masing-masing siswa. Sehingga konsep pelatihan tersebut menjadi lebih praktis. Dengan menggali potensi guru, guru akan tampil sebagai penggerak, harapannya potensi murid dapat terus tergali, inovasi pendidikan akan terus mengalir, dan kualitas pendidikan dapat terus maju.

Merdeka Belajar tidak mungkin berhasil tanpa teknologi. Ada hal penting yang perlu digarisbawahi disini, bahwa penggunaan teknologi bukan semata-mata memindahkan data dari bentuk fisik ke bentuk digital. Mindset ini perlu segera diubah. Teknologi bukan sekedar wadah untuk memberi tugas dan materi pelajaran, namun perlu didampingi dengan inovasi, kreasi, kolaborasi, komunikasi, dan evaluasi selama penggunaan teknologi tersebut. Lagi-lagi hal ini tidak keluar dari esensi pendidikan yaitu kualitas guru dengan "panggilan jiwa" mengajar yang dimilikinya. Disini teknologi bukan sekadar model online saja melainkan bisa bermacammacam jenisnya, contohnya belajar melalui tayangan TVRI yang tengah digalakkan oleh Kemendikbud. Dalam penggunaan teknologi, siswa harus difasilitasi untuk aktif belajar bukan berpusat pada guru. Sekarang tidak ada tuntutan yang kuat siswa harus ikut ujian. Hal ini membuka kesempatan bagi guru dan pihak-pihak terkait untuk membuat inovasi-inovasi pembelajaran untuk kebutuhan belajar siswanya. Itulah prinsip merdeka belajar yang didorong penerapannya dalam pembelajaran. Dengan memaksimalkan teknologi maka akan terjadi akselerasi merdeka belajar. Namun, pandemi Covid-19 seolah membongkar bahwa akses pendidikan di Indonesia tidak merata, hal ini terkait dengan sarana dan prasarana. Sehingga terdapat kesenjangan yang besar antara mereka yang memiliki akses teknologi dengan yang tidak. Padahal, teknologi memiliki potensi pemerataan akses atau kesempatan mendapat akses yang setara terhadap materi dan pembelajaran yang sama.

Merdeka belajar dapat diwujudkan pula dengan memaksimalkan desain kurikulum. Pendidikan kita perlu "kenormalan baru" dari segi kurikulum dengan cara memaksimalkan implementasi kurikulum berdasarkan kenyataan yang ada di tengah pandemi saat ini. Adaptasi kurikulum bagi daerah yang mampu menggelar sistem pembelajaran online akan seperti apa. Sedangkan daerah yang hanya mampu belajar offline, adaptasi kurikulumnya bagaimana. Begitu pula dengan adaptasi guru dan dinas pendidikan di daerah tersebut. Hal ini tidak bisa disamaratakan, mengingat fasilitas penunjang pendidikan setiap daerah di Indonesia pun berbeda-beda. Dengan kesenjangan pendidikan yang masih begitu nyata, desentralisasi pendidikan dapat dimaksimalkan. Masing-masing daerah pasti memiliki sudut pandang dan kearifan lokal tersendiri untuk dapat dikembangkan dalam upaya bersama-sama mewujudkan SDM unggul. Terlebih dalam suasana "New Normal" sudah semestinya setiap pendidikan 
di daerah diberikan keleluasaan untuk MERDEKA.

Kegiatan Pelatihan bagi guru-guru di Madrasah Aliyah Al-Ittihad Belung Poncokusumo pada tanggal 07-28 Februari 2021 yag akan diselenggarakan di Madrasah Aliyah Al-Ittihad akan membuka wawasan bagi guru-guru tentang konsep pembelajaran di era merdeka belajar.

Melalui kegiatan ini diharapkan guruguru dapat meningkatkan kemampuan dalam mengelola kegiatan pembelajaran di sekolah merdeka secara aktif dan inovatif.

\section{METODE PELAKSANAAN}

Metode pelaksanaan meliputi langkah-langkah yang akan dilakukan oleh tim IKIP Budi Utomo Malang terkait dengan solusi dari permasalahan yang ditemui di MA Al-Ittihad. Adapun langkah-langkah yang akan dilakukan, sebagai berikut:

1. Pembuatan materi untuk sosialisasi jenis media pembelajaran mutakhir yang dapat digunakan saat proses pembelajaran berlangsung.

2. Pemilihan narasumber ahli untuk sosialisasi jenis media pembelajaran.

3. Pembuatan modul pelatihan untuk guruguru MA Al-Ittihad.

4. Penyediaan sarana penunjang untuk praktek pembuatan dan penggunaan multimedia yang dibimbing oleh ahli.

Dalam segi sosial, Program Kepada Masyarakat (PKM) dapat dilakukan dengan cara:

1. Adanya sosialisasi yang bersifat interaktif, dimana guru-guru dapat bertanya langsung kepada narasumber.

2. Peran aktif mahasiswa IKIP Budi Utomo Malang dapat membantu proses berjalannya acara pengabdian kepada masyarakat ini.
Setelah Program Kepada Masyarakat (PKM) selesai dilaksanakan, tingkat keberhasialan dapat diukur dari:

1. Tercapainya target luaran yang telah direncakan sebelum kegiatan dilaksanakan.

2. Tanggapan guru-guru melaui kuesioner yang diberikan tentang sosialisasi dan pelatihan multimedia dalam proses pembelajaran sebagai pemantapan Iptek.

\section{HASIL DAN PEMBAHASAN}

\begin{tabular}{rrr}
\multicolumn{2}{c}{ Dalam melaksanakan } & Program \\
Kepada & Masyarakat & (PKM)
\end{tabular} mensosialisasikan peranan multimedia dalam proses pembelajaran, tim IKIP Budi Utomo Malang akan mengundang narasumber yang ahli dalam bidang Teknologi Pendidikan (TEP). Terdapat lima pergeseran pada proses pembelajaran dengan dikembangkannya teknologi, yaitu 1) konsep pelatihan beranjak ke penampilan, 2) lokasi yang statis di ruang kelas dan lingkungan sekolah, berubah menjadi dimana saja dan kapan saja, 3) paradigma paper based berubah menjadi less paper dengan menggunakan media online, 4) fasilitas fisik ke fasilitas jaringan kerja dan 5) dari waktu siklus ke waktu nyata (Rosenberg, 2001). Narasumber akan memberikan motivasi kepada siswa untuk belajar bahasa Inggris.

Dari permasalahan yang ditemukan pada mitra PKM (MA Al-Ittihad), adapun beberapa hal yang telah dilakukan sebagai solusi dari permasalahan tersebut, yaitu:

1. Memberikan sosialisasi tentang jenis-jenis medi mutakhir yang dapat digunakan pada proses pembelajaran. Adapun beberapa jenis-jenis multimedia interaktif berbasis komputer yaitu, model drills, model tutorial, model simulasi, dan model instructional games (Rusman 2005 dalam Nandi, 2006: 5). Sosialisasi ini diharapkan mampu memberikan dampak positif bagi guru-guru untuk memanfaatkan Iptek dalam proses pembelajaran. 
2. Memberikan pelatihan pembuatan multimedia sederhana yang dapat digunakan saat proses pembelajaran berlangsung. Dengan adanya media pembelajaran yang mutakhir, siswa diharapkan memiliki motivasi belajar yang lebih baik.

3. Memberikan pelatihan penggunaan multimedia yang telah dibuat pada proses pembelajaran. Guru dapat memanfaatkan sarana penunjang seperti LCD projector dan laptop saat pembelajaran berlangsung.

4. Mendatangkan 10 penutur asing yang merupakan mahasiswa IKIP Budi Utomo untuk berinteraksi dengan siswa yang ada di sana.

Adapun 2 mahasiswa yang dilibatkan dapat menjadi penggerak bagi guru-guru di MA Al-Ittihad untuk "melek" teknologi. Selain itu, mahasiswa diharapkan dapat menambah pengangalaman lapangan terkait dengan dunia pendidikan.

Kegiatan pelaihan ini bertujuan untuk meningkatkan SDM guru dalam mengikuti era perkembangan pendidikan di masa sekarang. Guru seharusnya mempunyai kemampuan dalam bidang studi (kepakaran ilmu), dapat memahami kurikulum, menguasai berbagai metodologi penilaian, menciptakan lingkungan belajar yang kondusif dan melakukan pengembangan professional (Ono \& Ferriera, 2010). Pelatihan SDM guru dengan teman 'Transformasi Pembelajaran di Era Merdeka Belajar' merupakan salah satu bentuk kerjasama antara IKIP Budi Utomo dengan Aliyah Al -Ittihad Belung Poncokusumo. Kegiatan tersebut merupakan salah satu bentuk implementasi TRI DARMA Perguruan Tinggi. Pelatihan/ workshop ini dilaksanakan pada 07-28 Februari 2021 yang bertempat di Aula Madrasah Aliyah Al Ittihad. Berikut ini adalah peserta dan pemateri pada kegiatan tersebut:

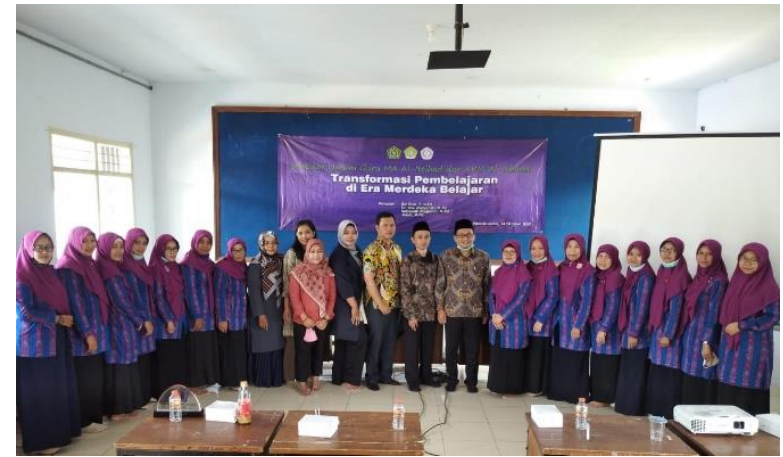

Gambar 1. Peserta dan pemateri kegiatan workshop

Pada tahap pertama kegiatan pelatihan akan di buka oleh Bapak Kepala Sekolah Madrasah Aliyah Al Ittihad dan sambutan selanjutnya oleh Bapak Kaprodi Pendidikan Bahasa Inggris IKIP Budi Utomo Malang, dan sekaligus dilakukan penandatanganan MOU antara IKIP Budi Utomo dan Madrasah Aliyah Al-Ittihad Belung Poncokumo. Berikut ini adalah dokumentasi penandatanganan MoU yang kami lakukan:

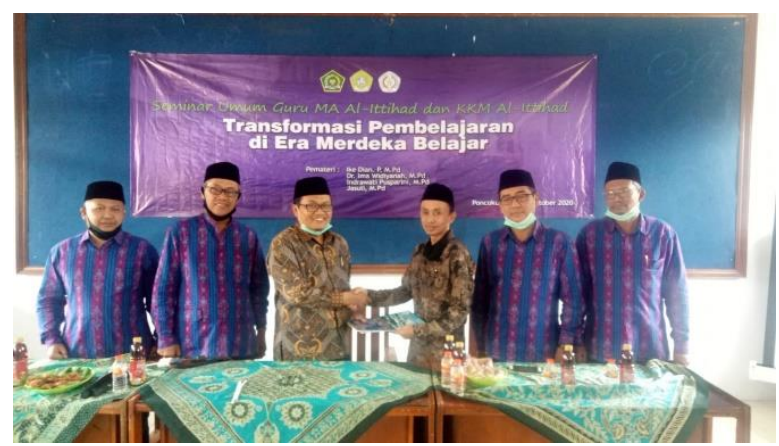

Gambar 2. Penandatangan MoU kegiatan

Pada tahap kedua dengan menghadirkan nara sumber yang ahli pada bidang pendidikan atau praktisi pendidikan yang disampaikan oleh Jasuli, M.Pd dengan materi tentang media pembelajaran.

Pada sesi ketiga dilanjutkan oleh pemateri selanjutnya yaitu ibu Ike Dian Puspita Sari, M.Pd dengan materi tentang transformasi pembelajaran dengan berbasis e-learning memanfaatkan multimedia. Multimedia sangant erat kaitannya dengan penggunaan gadget untuk menyajikan dan menggabungkan teks, suara, gambar, animasi dan video dengan alat bantu bernavigasi, berinteraksi, berkarya dan 
berkomunikasi (Satria, 2005). Menurut Sadiman (2010) ada empat manfaat dalam menggunakan multimedia dalam proses pembelajaran, diantaranya adalah 1) untuk memperjelas pesan yang disampaikan agar tidak terlalu bersifat verbal, 2) mengatasi keterbatasan ruang, waktu, 3) mengatasi sifat pasif siswa, dan 4) mempermudah guru dalam menyampaikan isi materi pelajaran.

Pada sesi ke empat dilanjutkan oleh pemateri Ibu Indrawati Pusparini, M.Pd, dengan materi model pembelajaran dan kegiatan-kegiatan ice breaker yang bertujuan untuk berbagi infromasi dan gambaran atau arahan teknis tentang transformasi pembelajaran di era merdeka belajar dengan memanfaatkan teknologi dan dapat diterima.

Pada tahap terakhir pelatihan dilakukan dengan menghadirkan praktisi bidang menajemen kependidikan yang akan di sampaikan oleh Dr. Ima Widiyanah, S.Pd, M.Pd yang akan membahas tentang metode pembelajaran di era merdeka belajar dan transformasi pembelajaran konvensional ke pembelajaran yang yang lebih inovatif dan kreatif untuk mendukung berlangsungnya era merdeka belajar dan akan membahas tentang pengantar pelaksanaan AKM (Assesment Kompetensi Minimum).

Tahapan selanjutnya dilakukan Tanya jawab pada pemateri pertama dan pemateri kedua yang terkait dengan topik pembahasan tersebut.

\section{KESIMPULAN}

Perkembangan ilmu pengetahuan dan teknologi semakin mendorong upaya-upaya pembaharuan dalam pemanfaatan hasil hasil teknologi dalam proses belajar. Media yang dapat menunjang pembelajaran diantaranya adalah media komputer. Di era pandemic, pembelajaran jarak jauh sangat dibutuhkan dan dianjurkan untuk menekan penyebaran COVID 19.

Ada banyak platform media pembelajaran yang dapat digunakan selama pembelajaran jarak jauh pada saat ini. Guru dituntut dapat mengembangkan keterampilan membuat media ataupun mengembangkan media pembelajaran karena metode dan media pembelajaran yang digunakan oleh guru sangat berpengaruh terhadap hasil proses belajar mengajar. Tetapi untuk membuat media tersebut dibutuhkan kemampuan dan pengetahuan, dimana tidak setiap guru mempunyai kemampuan untuk itu. oleh karena itu perlu adanya pelatihan pembuatan media pembelajaran berbasis online yang akan digunakan selama pandemic dan pembelajaran jarak jauh.

\section{DAFTAR PUSTAKA}

Nandi. 2006. Penggunaan multimedia Interaktif dalam Pembelajaran Geografi di Persekolahan. Jurnal "GEA" Jurusan Pendidikan Geografi, 6. (1), April 2006.

Ono, Y. dan Ferriera, J. 2010. A case study of continuing teacher professional development through lesson study in South Africa. South African Journal od Education. 30, pp. 59-74

Rosenberg. 2001. E-Learning: Strategies for Delivering Knowledge in The Digital Age. McGraw-Hill Professional Companies

Sadiman, A.S. 2010. Media Pendidikan. Jakarta: Rajawali Pers

Satria. 2005. Apa itu Multimedia. (online). www.satriamultimedia.com/artikel_a pa_itu_multimedia.html diakses 20 April 2021 